\title{
SURVEI KEMAMPUAN TEKNIK DASAR BULUTANGKIS SISWA PESERTA EKSTRAKURIKULER SMA PATRA MANDIRI 1 PLAJU
}

\author{
Oleh : Mutiara Fajar, M.Pd \\ (Universitas PGRI Palembang) \\ Mutiarafajar89@gmail.com
}

\begin{abstract}
Abstrak
Belum pernah diadakannya evaluasi keterampilan teknik dasar bulutangkis ekstrakurikuler di SMA Patra Mandiri 1 Palembang merupakan dasar penelitian ini dilakukan. Agar dapat mengetahui tingkat keterampilan teknik dasar permainan bulutangkis, wall volley, servis pendek, servis panjang, dan clear tes Siswa. Desain penelitian ini menggunakan deskriptif metode survei untuk teknik tes dan pengukuran. Populasi penelitian seluruh siswa yang mengikuti ekstrakurikuler bulutangkis, berjumlah 21 siswa putra. Penelitian ini menggunakan populasi keseluruhan sebagai sampel. Instrumen dalam penelitian ini menggunakan tes Fenanlampir yang dipakai tes wall volley, servis pendek, servis panjang, dan clear tes. Skor yang diperoleh kemudian dianalisis dengan teknik statistik yang dituangkan dalam bentuk persentase. Berdasarkan penelitian dan pembahasan dapat disimpulkan bahwa kemampuan teknik dasar bulutangkis siswa yang mengikuti kegiatan ekstrakurikuler bulutangkis di SMA Patra Mandiri 1 Palembang kategori baik dengan tes wall volley katagori baik sebesar 33,33\% dan katagori cukup sebesar 66,67\%, untuk tes servis pendek kategori baik sekali sebesar $27,78 \%$, kategori baik sebesar 66,67\%, kategori cukup sebesar 5,55\%, untuk tes servis panjang katagori baik sekali sebesar 2,78\% katagori baik sebesar 25,00\% katagori cukup sebesar 72,22\%, dan untuk clear tes katagori baik sebesar 16,67\%. Katagori cukup sebesar 38,89\%, kurang sebesar 44,44\%.
\end{abstract}

Kata kunci: Kemampuan, Teknik Dasar, Bulutangkis.

\section{THE SURVEY OF EXTRACURRICULAR STUDENTS BASIC TECHNIQUE ON BADMINTON ON SMA PATRA MANDIRI 1 PLAJU}

\begin{abstract}
The base thinking of this reserch is never has an evaluation before about basic technical skills of extracurricular badminton in Patra Mandiri 1 Palembang High School. The research aims to know the level of basic technical skills of playing badminton, wall volleyball, short service, long service, and clear Student tests. The design of this study uses descriptive survey methods for test and measurement techniques. The research population is all of students who took part in badminton extracurricular activities was 21 male students. This study uses the entire population as a sample. The instruments in this study used the Fenanlampir test which used a wall volley test, short service, long service, and clear test. The scores obtained were analyzed using statistical techniques as outlined in the form of percentages. Based on the research and discussion, it can be concluded that the basic technical abilities of badminton students who take part in badminton extracurricular activities at SMA Patra Mandiri 1 Palembang are good with $33.33 \%$ good wall volley tests and sufficient categories of $66.67 \%$, for short service tests categories very good at $27.78 \%$, good category at $66.67 \%$, sufficient category at $5.55 \%$, for long
\end{abstract}


service tests very good at $2.78 \%$ good categories at $25.00 \%$ enough categories at $72.22 \%$ , and to clear the good category test by $16.67 \%$. The enough categories are $38.89 \%$, less than $44.44 \%$.

Keywords: Ability, Basic Techniques, Badminton.

Correspondence author: Mutiara Fajar, Universitas PGRI Palembang, Indonesia. mutiarafajar89@gmail.com (c) (i) (2)

Jurnal HalamanOlahraga Nusantara licensed under a Creative Commons Attribution-ShareAlike 4.0 International License.

\section{PENDAHULUAN}

Pendidikan adalah suatu proses pembelajaran yang digunakan untuk menambah pengetahuan, kemampuan serta keterampilan dalam diri manusia sehingga berdampak membuat perubahan pola fikir, sifat serta gerak yang menuju kearah yang lebih baik atau dari yang tidak tahu menjadi tahu, dari yang tidak bisa menjadi bisa. Menurut (Rusmaini 2004) “Apabila kita tinjau dari rumusan bahasa sebagai mana yang tercantum dalam kamus besar bahasa indonesia disebutkan bahwa pendidikan adalah proses perubahan sikap dan tata laku seseorang atau kelompok orang dalam usaha mendewasakan manusia melalui upaya pengajaran dan pelatihan".

Pendidikan sangatlah penting untuk kehidupan manusia, karena dengan pendidikan dapat mendukung perubahan keterampilan gerak dan pola fikir. Keberhasilan dalam bidang pendidikan sangat ditentukan oleh keberhasilan dalam proses pembelajaran. Proses pembelajaran merupakan serangkaian interaksi antara manusia yaitu yang mengajar atau yang biasa disebut guru dengan orang yang diajar atau yang disebut siswa. Ada banyak cara untuk memperoleh kebugaran jasmani, misalnya dalam satuan pendidikan, telah diatur dalam kurikulum pendidikan jasmani dengan tujuan agar siswa memperoleh cara-cara yang baik dalam meraih kebugaran. Dalam kehidupan sehari-hari orang-orang biasanya memanfaat lahan kosong atau track jogging untuk memperoleh kebugaran jasmani (Kumbara 2019)

Adapun pendidikan yang sangat baik untuk meningkatkan keterampilan gerak dan pola fikir adalah pendidikan jasmani olahraga dan kesehatan, dimana 
dalam pendidikan jasmani olahraga dan kesehatan peserta didik diajarkan konsep belajar, bermain, berkolaborasi, dan menjunjung tinggi nilai sportifitas. Menurut (Rahayu 2013) pendidikan jasmani merupakan media untuk mendorong Perkembangan keterampilan motoric, kemampuan fisik, pengetahuan, penalaran, penghayatan nilai (sikap-mental-emos ional-spiritual-sosial), dan pembiasaan pola hidup sehat yang bermuara untuk merangsang pertumbuhan serta perkembangan yang seimbang.

Pendidikan jasmani olahraga dan kesehatan adalah salah satu mata pelajaran yang sangat menyenangkan karena di dalam pelajaran pendidikan jasmani olahraga dan kesehatan siswa dapat melakukan kegiatan belajar, bermain, dan berkolaborasi bersama teman atau timnya, yang dalam proses pembelajarannya mengutamakan aktivitas jasmani dan kebiasaan hidup sehat menuju pada pertumbuhan dengan pengembangan jasmani, mental, dan sosial, yang sesuai, serasi, dan seimbang.Pendidikan jasmani ada tiga hal penting yang bisa menjadi sumbangan unik. 1.Meningkatkan kebugaran jasmani dan kesehatan siswa, 2.Meningkatkan terkuasainya keterampilan fisik yangkaya, serta 3.Meningkatkan pengertian siswa dalam prinsip-prinsip gerak serta bagaimana menerapkannya dalam praktik menurut Dauwer and Pangrazy (dikutip dari (Rahayu 2013) Kegiatan pembelajaran yang dilaksanakan di sekolah terbagi menjadi beberapa macam-macam sebagai contoh yaitu permainan bola besar, bola kecil, permainan target, aktivitas ritmik, senam kelentukan dan lain-lain.

Dalam mengembangkan keterampilan gerak anak dalam pendidikan jasmani sebenarnya sudah tidak sulit lagi untuk dilakukan karena telah banyak cara dan metode yang dapat digunakan dan telah dikembangkan pada masa ini, tetapi pada kenyataannya dibeberapa sekolah masih terhambat dengan guru yang mengajar dengan cara yang monoton dan kurang kreatif karena disebabkan oleh beberapa hal dan guru yang kurang tepat dalam menerapkan metode pendidikan jasmani sehingga masih belum mencapai tujuan dalam pendidikan jasmani yang sebenarnya.

Pada dasarnya tujuan pembelajaran Pendidikan Jasmani Olahraga dan Kesehatan di sekolah membantu peserta didik dapat meningkatkan kemampuan 
dan keterampilan gerak dasar.Menurut (Harsuki 2003) "Para pakar pendidikan jasmani kurang lebih sependapat bahwa tujuan pendidikan jasmani adalah (1) pertumbuhan-pertumbuhan organ tubuh untuk meningkatkan kesehatan dan kebugaran jasmani, (2) perkembangan neuro muscular, (3) perkembangan mental emosional, (4) perkembangan sosial dan (5) perkembangan intelektual”.

Melihat dari pendidikan jasmani yang di terapkan disekolah menuntut siswa untuk mempelajari beberapa materi dan jenis cabang olahraga dan permainan,diantaranya adalah permainan bulutangkis.Akan tetapi dengan melihat kenyataan yang ada, bahwa Pendidikan Jasmani Olahraga dan Kesehatan yang hanya 2 (dua) jampelajaran perminggu diperkirakan belum memenuhi apa yang diinginkan untuk mencapai tujuan Pendidikan Jasmani Olahraga dan Kesehatan tersebut. Ekstrakurikuler olahraga merupakan salah satu solusi untuk dapat mencapai tujuan Pendidikan Jasmani khususnya dalam cabang olahraga bulutangkis. Jika kegiatan Ekstrakurikuler dilaksanakan dengan baik, terencana dan berkesinambungan diharapkan dapat meningkatkan salah satu keterampilan siswa dalam cabang olahraga bulutangkis khususnya. Ekstrakurikuler dapat membantu meningkatkan pertumbuhan dan perkembangan siswa serta siswa juga dapat memperdalam dan memperluas pengetahuan yang berkaitan dengan keterampilan masing-masing cabang olahraga, pembentukan nilai-nilai kepribadian siswa, serta memunculkan bakat siswa yang berprestasi dalam bidangnya, dalam cabang olahraga bulutangkis misalnya.

Kegiatan ekstrakurikuler yang diselenggarakan di SMA Patra Mandiri 1 Plaju bermacam-macam. Kegiatan tersebut ada yang berorientasi di bidang olahraga, kesenian, agama, Pramuka dan lain-lainnya.Peserta didik diwajibkan memilih salah satu kegiatan ekstrakurikuler sesuai dengan bakat dan minat. Adapun kegiatan ekstrakurikuler dalam bidang olahraga yang diselenggarakan di SMA Patra Mandiri 1 Plaju antara lain adalah sepak bola, futsal, bolabasket, bolavoli, dan bulutangkis.

Hasil observasi di SMA Patra Mandiri 1 Plaju memiliki sarana dan prasarana yang cukup memadai, namun prestasinya belum mampu bersaing dengan sekolah lain dalam bidang olahraga, khususnya cabang olahraga 
bulutangkis di kota Palembang. Melalui wawancara yang dilakukan dengan pelatih ekstrakurikuler bulutangkis di SMA Patra Mandiri 1 Plaju lebih banyak dilakukan melalui latihan dalam bentuk permainan dengan pemberian teknik dasar. Kegiatan ekstrakurikuler bulutangkis di SMA Patra Mandiri 1 Plaju diikuti oleh 21 siswa.

Dalam kegitan latihan masih banyak siswa yang mempunyai teknik dasar bermain bulutangkis yang kurang baik. Kemampuan siswa dalam melakukan teknik dasar bulutangkis masih sering menemui kesalahan seperti servis pendek yang tidak sampai atau nyangkut di jaring net, servis panjang yang tanggung, dalam melakukan smash bola tidak bergerak menukik ke bawah dengan keras dan bahkan bola melaju horizontal dan keluar lapangan. Teknik dasar merupakan hal yang penting dalam suatu cabang olahraga bulutangkis, karena teknik dasar akan menentukan cara melakukan suatu gerakan dasar yang baik.

Permasalahan yang muncul pada saat kegiatan pembelajaran Pendidikan Jasmani khususnya bulutangkis di SMA Patra Mandiri 1 Plaju adalah belum diketahui secara pasti kemampuan dari masing-masing siswa dalam bermain bulutangkis, sehingga dari hal tersebut perlu adanya sebuah penelitian yang meneliti dan membahas tentang keterampilan bermain bulutangkis. Untuk itu perlu diadakan penelitian, tentang tingkat kemampuan Teknik dasar bulutangkis di kegiatan ekstrakurikuler SMA Patra Mandiri 1 Plaju.Untuk mengetahui hal tersebut maka perlu dilakukan penelitian dengan judul "Survei kemampuan teknik dasar bulutangkis siswa peserta ekstrakurikuler bulutangkis SMA Patra Mandiri 1 Plaju".

\section{METODE}

Penelitian ini adalah merupakan penelitian deskriptif (Arikunto 2010) Penelitian deskriptif merupakan penelitian yang paling dimaksudkan untuk menginformasikan mengenai status gejala yang ada, yaitu gejala menurut apa adanya pada saat penelitian dilakukan". Dengan menggunakan metode survei yang menggunakan tes pengukuran yaitu : Wall Volley, Servis Pendek, Servis Panjang, dan Clear Tes. 


\section{DEFINISI OPERASINAL VARIABEL}

Menurut (Sugiyono 2016)“variabel penelitian pada dasarnya adalah segala sesuatu yang berbentuk apa saja yang ditetapkan oleh peneliti untukdipelajari sehingga diperoleh informasi tentang hal tersebut, kemudian ditarik kesimpulannya".

Variabel dalam penelitian ini adalah kemampuan teknik dasar bulutangkis.Secara operasional variabel tersebut dapat didefinisikan sebagai variabel tunggal kemampuan teknik dasar bulutangkis.Kemampuan teknik dasar bulutangkisdiketahui dengan cara tes keterampilan dasar bulutangkis. Menurut (Fenanlampir A 2015) "Bahwa tes keterampilan bermain bulutangkis dimaksudkan untuk mengklasifikasi pemain, mengukur kemajuan, dan dipakai juga sebagai dasar evaluasi atas kecakapan para pemain”. Keterampilan dasar yang dihitung atau di tes yaitu: a) Wall Volley, b) short service, c)long service, dan d)clear tes.yang dilakukan oleh peserta ekstrakurikuler bulutangkis SMA Patra Mandiri 1 Plaju.

\section{TEKNIK ANALISIS DATA}

Data yang sudah terkumpul perlu dianalisis agar dapat diambil kesimpulan. Suatu data tidak akan ada artinya jika tidak melalui proses analisis, maka dari itu analisis data merupakan langkah penting dalam suatu penelitian. Urutan menganalisis data yang diperoleh dengan cara mencatat angka atau nilai yang diperoleh berdasarkan tes yang telah dilakukan oleh masing-masing testi. Kemudian Nilai yang diperoleh dari tes: a) Wall Volley, b) short service, c)long service, dan d) clear tes. dikonsultasikan dengan tabel norma tes keterampilan Bulutangkis. 
Tabel Norma Tes Keterampilan Bulutangkis

\begin{tabular}{|c|c|}
\hline SKOR TES & KLASIFIKASI \\
\hline $933,82-$ KE ATAS & SEMPURNA \\
\hline $824,27-933,81$ & SANGAT BAIK \\
\hline $714,72-829,26$ & BAIK \\
\hline $605,17-714,71$ & CUKUP \\
\hline $495,62-605,16$ & SEDANG \\
\hline $386,07-495,61$ & KURANG \\
\hline $276,52-386,06$ & BURUK \\
\hline $166,52-276,51$ & SANGAT BURUK \\
\hline $57,42-166,96$ & TIDAK ADA SKIL \\
\hline
\end{tabular}

Sumber :(Fenanlampir,2015:192)

Adapun kegiatan-kegiatan yang dilakukan dalam menganalisis dan mengolah data sebagai berikut :

1. Editing yaitu mengecek semua data yang dikumpulkan.

2. Tabulasi yaitu proses pembuatan tabel memasukkan data kedalam bagan tabel dan pemberian nilai terhadap item-item yang perlu diberi nilai.

3. Mengklasifikasi nilai yang diperoleh siswa dalam skala yang telah ditentukan.

4. Mempresentasikan data yang telah dihitung perkategorinya dengan rumus.

$$
\begin{aligned}
\text { Dp } & =\frac{n}{N} \times 100 \% \\
\text { Dp } & =\text { deskriptif presen } \\
\mathrm{n} & =\text { jumlah nilai yang diperoleh } \\
\mathrm{N} & =\text { jumlah keseluruhan nilai }
\end{aligned}
$$

5. Menyimpulkan hasil penelitian sehingga diperoleh deskripsi tentang kemampuan teknik dasar bulutangkis pada siswa ekstrakurikuler SMA Patra Mandiri 1 Plaju. 


\section{HASIL DAN PEMBAHASAN}

Secara sistematis penyajian data dalam penelitian diperoleh dari 21 siswa Putra SMA Patra Madiri 1 Palembang berkaitan dengan teknik dasar pukulan bulu tangkis. Berdasarkan analisis deskriptif yang dilakukan disajikan dalam tabel sebagai berikut:

Nilai Teknik Dasar Pukulan Bulu Tangkis Siswa Putra Sma Patra Madiri 1 Palembang

\begin{tabular}{|c|c|c|c|}
\hline Indikator & N & Min & Max \\
\hline Wall Volley & 21 & 42 & 74 \\
\hline Servis Pendek & 21 & 60 & 92 \\
\hline Servis Panjang & 21 & 41 & 82 \\
\hline Clear Tes & 21 & 22 & 72 \\
\hline
\end{tabular}

\section{Keterampilan Wall Volley}

Berdasarkan analisis persentase yang dilakukan didapatkan nilai keterampilan Wall Volley disajikan dalam tabel sebagai berikut:

Persentase Nilai Keterampilan Wall Volley Bulu Tangkis Siswa siswa Putra Sma Patra Madiri 1 Palembang

\begin{tabular}{|c|c|c|c|c|}
\hline No & Nilai & Katagori & Frekuensi & Persentase \\
\hline 1 & $81-100$ & Baik Sekali & 0 & $0 \%$ \\
\hline 2 & $61-80$ & Baik & 7 & $33,33 \%$ \\
\hline 3 & $41-60$ & Cukup & 14 & $66,67 \%$ \\
\hline 4 & $21-40$ & Kurang & 0 & $0 \%$ \\
\hline 5 & $1-20$ & Kurang Sekali & 21 & $100 \%$ \\
\hline
\end{tabular}

\section{Keterampilan servis pendek backhand}

Berdasarkan analisis persentase yang dilakukan didapatkan nilai keterampilan servis pendek backhand disajikan dalam tabel sebagai berikut: 
Tabel Persentase Nilai Keterampilan Servis Pendek Backhand Bulu Tangkis

Siswa

\begin{tabular}{|c|c|c|c|c|}
\hline No & Nilai & Katagori & Frekuensi & Persentase \\
\hline 1 & $81-100$ & Baik Sekali & 6 & $27,78 \%$ \\
\hline 2 & $61-80$ & Baik & 14 & $66,67 \%$ \\
\hline 3 & $41-60$ & Cukup & 0 & $5,55 \%$ \\
\hline 4 & $21-40$ & Kurang & 0 & $0 \%$ \\
\hline 5 & $1-20$ & Kurang Sekali & 21 & $100 \%$ \\
\hline
\end{tabular}

\section{Keterampilan Servis Panjang}

Berdasarkan analisis persentase yang dilakukan didapatkan nilai keterampilan Servis Panjang disajikan dalam tabel sebagai berikut:

Tabel Persentase Nilai Keterampilan Servis Panjang Bulu Tangkis Siswa

\begin{tabular}{|c|c|c|c|c|}
\hline No & Nilai & Katagori & Frekuensi & Persentase \\
\hline 1 & $81-100$ & Baik Sekali & 1 & $2.78 \%$ \\
\hline 2 & $61-80$ & Baik & 5 & $25.00 \%$ \\
\hline 3 & $41-60$ & Cukup & 15 & $72.22 \%$ \\
\hline 4 & $21-40$ & Kurang & 0 & $0 \%$ \\
\hline 5 & $1-20$ & Kurang Sekali & 0 & $0 \%$ \\
\hline \multicolumn{5}{|c|}{ Jumlah } \\
\hline
\end{tabular}

\section{Keterampilan clear tes}

Berdasarkan analisis persentase yang dilakukan didapatkan nilai keterampilan Clear tes disajikan dalam tabel 7 sebagai berikut:

Tabel Persentase Nilai Keterampilan clear tes Bulu Tangkis Siswa

\begin{tabular}{|c|c|c|c|c|}
\hline No & Nilai & Katagori & Frekuensi & Persentase \\
\hline 1 & $81-100$ & Baik Sekali & 0 & $0 \%$ \\
\hline 2 & $61-80$ & Baik & 3 & $14,28 \%$ \\
\hline 3 & $41-60$ & Cukup & 8 & $38,1 \%$ \\
\hline 4 & $21-40$ & Kurang & 0 & $47,61 \%$ \\
\hline 5 & $1-20 \quad$ Kurang Sekali & 21 & $0 \%$ \\
\hline & \multicolumn{2}{|c|}{ Jumlah } & $100 \%$ \\
\hline
\end{tabular}


Agar dapat diambil kesimpulan. Suatu data tidak akan ada artinya jika tidak melalui proses analisis, maka dari itu analisis data merupakan langkah penting dalam suatu penelitian. Urutan menganalisis data yang diperoleh dengan cara mencatat angka atau nilai yang diperoleh berdasarkan tes yang telah dilakukan oleh masing-masing testi. Kemudian Nilai yang diperoleh dari tes: a) Wall Volley, b) servic pendek, c) servic panjang, dan d) clear tes. dikonsultasikan dengan tabel norma tes keterampilan Bulutangkis.

NORMA TES KETERAMPILAN BULUTANGKIS

\begin{tabular}{|c|c|}
\hline SKOR TES & KLASIFIKASI \\
\hline $933,82-$ KE ATAS & SEMPURNA \\
\hline $824,27-933,81$ & SANGAT BAIK \\
\hline $714,72-829,26$ & BAIK \\
\hline $605,17-714,71$ & CUKUP \\
\hline $495,62-605,16$ & SEDANG \\
\hline $386,07-495,61$ & KURANG \\
\hline $276,52-386,06$ & BURUK \\
\hline $166,52-276,51$ & SANGAT BURUK \\
\hline $57,42-166,96$ & TIDAK ADA SKIL \\
\hline
\end{tabular}

Sumber :(Fenanlampir,2015:192).

\section{PEMBAHASAN}

Berdasarkan hasil penelitian yang telah dilakukan berkaitan dengan keterampilan teknik dasar pukulan bulu tangkis maka secara umum keterampilan tersebut berada dalam katagori memuaskan, dimana berdasarkan beberapa keterampilan diantaranya Wall volley keterampilan yang ditunjukan siswa ratarata cukup. Servis pendek keterampilan yang ditunjukan siswa rata-rata baik sekali. Servis panjang keterampilan yang ditunjukan siswa rata-rata baik. Pukulan clear yang ditunjukan siswa rata-rata cukup.

Hasil yang ditunjukan tersebut didukung oleh catatan lapangan berdasarkan observasi yang telah peneliti lakukan diantaranya dengan pengukuran keterampilan dengan kisi-kisi penilaian melalui 5 katagori nilai siswa menunjukan 
penampilan gerak yang baik khususnya pada keterampilan servis. Selanjutnya untuk Wall volley juga sama namun keterampilan yang ditunjukan sedikit dibawah keterampilan servis yang nilainya lebih baik. Sedangkan untuk keterampilan clear tes siswa belum sepenuhnya terampil baik karena 47,61 \% siswa hanya menampilkan dan dikatagorikan kurang.

Hasil tersebut juga didukung oleh wawancara yang dilakukan dengan pelatih ekstrakurikuler bulutangkis dimana hasil tersebut dikarenakan pada saat latihan yang diberikan siswa cukup antusias dalam mengikuti proses latihan, selanjutnya pemenuhan media latihan berkaitan dengan jumlah raket dan shuttle cook dengan banyaknya jumlah siswa seimbang karena khusus dalam ekstrakurikuler bulu tangkis siswa rata-rata memiliki media tersebut.

Penguasaan keterampilan teknik dasar pukulan juga dapat dikuasai dengan baik karena rata-rata siswa mengikuti kegiatan latihan yang dilaksanakan di ekstrakurikuler bulu tangksi. Adapun jumlah siswa yang mengikuti kegiatan tersebut berkisar 21 orang berdasarkan hasil observasi yang dilakukan pada siswa. Penguasaan keterampilan tersebut tentu saja dapat diaplikasikan dalam proses latihan karena dengan kegiatan tambahan yang dilakukan berkaitan dengan keterampilan bermain bulu tangkis akan dapat ditunjukan dalam proses latihan sebagai nilai tambah yang dimiliki oleh siswa.

Proses penelitian melalui kegiatan observasi yang dilakukan dapat menunjukan hasil latihan yang ditampilkan oleh siswa berkaitan dengan penlilaian psikomotorik atau keterampilan gerak dalam proses pembelajaran dimana siswa sudah dapat memahami dan mempraktikan keterampilan yang diajarkan pada proses belajar mengajar dengan hal tersebut tentu saja akan dapat mencapai nilai yang baik pula dalam kegiatan latihan. Adapun beberapa keterbatasan dalam proses penelitian yang menjadi kendala antara lain adalah pengkoordiniran siswa dengan jumlah siswa yang cukup besar menjadi salah satu tantangan utama dalam penelitian. 


\section{KESIMPULAN}

Berdasarkan hasil penelitian dan pembahasan dapat disimpulkan bahwa kemampuan teknik dasar bulutangkis siswa yang mengikuti kegiatan ekstrakurikuler bulutangkis di SMA Patra Mandiri 1 Palembang kategori baik dengan tes wall volley katagori baik sebesar 33,33\% dan katagori cukup sebesar $66,67 \%$, untuk tes servis pendek kategori baik sekali sebesar 27,78\%, kategori baik sebesar $66,67 \%$, kategori cukup sebesar 5,55\%, untuk tes servis panjang katagori baik sekali sebesar 2,78\% katagori baik sebesar 25,00\% katagori cukup sebesar 72,22\%, dan untuk clear tes katagori baik sebesar 16,67\%. Katagori cukup sebesar $38,89 \%$, kurang sebesar $44,44 \%$.

\section{DAFTAR PUSTAKA}

Arikunto, Suharsimi. 2010. "Prosedur Penelitian Sebuah Pendekatan Praktek." Jakarta: Rineka Cipta.

Fenanlampir A, Faruq MM. 2015. “Tes Dan Pengukuran Dalam Olahraga.” Yogyakarta : CV ANDI OFFSET

Harsuki, H. 2003. “Perkembangan Olahraga Terkini Kajian Para Pakar.” Jakarta: PT. Raja Grafindo Persada.

Kumbara, Hengki. 2019. "Survei Minat Member Yang Mengikuti Fitness Pada Pusat Kebugaran Kota Palembang. Jurnal Halaman Olahraga Nusantara.” (http://garuda.ristekbrin.go.id/documents/detail/1459411.).

Rahayu, Ega T. 2013. "Strategi Pembelajaran Pendidikan Jasmani." Bndung: Alfabeta.

Rusmaini. 2004. "Ilmu Pendidikan.” Palembang: Grafika Telindo Press.

Sugiyono. 2016. "Metode Penelitian Pendidikan (Pendekatan Kuantitatif,Kualitatif, Dan R\&D).” Bandung: Alfabeta. 